\title{
Evidence for the long term cost effectiveness of home care reablement programs
}

This article was published in the following Dove Press journal:

Clinical Interventions in Aging

I October 2013

Number of times this article has been viewed

\section{Gill F Lewin ${ }^{1,2}$ \\ Helman S Alfonso 3 \\ Janine J Alan ${ }^{4}$}

'Faculty of Health Sciences, Curtin University, Perth, WA, Australia;

${ }^{2}$ Research Department, Silver Chain Group, Perth,WA, Australia; ${ }^{3}$ School of Population Health, University of Western Australia, Perth, WA, Australia; ${ }^{4}$ Faculty of Health Sciences, Curtin University, Perth, WA, Australia

Correspondence: Gill F Lewin Faculty of Health Sciences, Curtin University, GPO Box UI 987, Perth, WA 6845, Australia $\mathrm{Tel}+6 \mid 892661829$

Fax +61 892662508

Email g.lewin@curtin.edu.au
Background: The objectives of this study were to determine whether older individuals who participated in a reablement (restorative) program rather than immediately receiving conventional home care services had a reduced need for ongoing support and lower home care costs over the next 57 months (nearly 5 years).

Materials and methods: Data linkage was used to examine retrospectively the service records of older individuals who had received a reablement service versus a conventional home care service to ascertain their use of home care services over time.

Results: Individuals who had received a reablement service were less likely to use a personal care service throughout the follow-up period or any other type of home care over the next 3 years. This reduced use of home care services was associated with median cost savings per person of approximately AU $\$ 12,500$ over nearly 5 years.

Conclusion: The inclusion of reablement as the starting point for individuals referred for home care within Australia's reformed aged care system could increase the system's cost effectiveness and ensure that all older Australians have the opportunity to maximize their independence as they age.

Keywords: restorative, older adults, community dwelling, service costs

\section{Introduction}

Australia is in the process of reforming its aged care system. The Living Longer Living Better aged care reform package includes recognition of the need for a strong focus on independence, rehabilitation, and restorative care. This will be achieved by establishment of an integrated Commonwealth home support program by July 1, 2015 that seeks to maximize preventative and restorative care to optimize outcomes for care recipients and avoid unnecessary progression to more intensive, higher cost services. ${ }^{1}$ These reforms are based on the recommendations of the Productivity Commission's 2010/2011 inquiry into caring for older Australians. ${ }^{2}$ The particular recommendation relevant to this paper being "An intensive re-ablement service should be introduced to give greater focus on independence, rehabilitation and restorative care[...]".

The Productivity Commission's recommendation and the subsequent government response are based on growing evidence of the effectiveness of reablement/restorative home care services in assisting older people to improve their ability to function and reduce their need for ongoing services. Few studies, however, have examined how long these beneficial effects last. In Australia, reablement has been described as having the following key components: 
1. an emphasis on capacity building or restorative care to maintain or promote a client's capacity to live as independently as possible, with an aim of improving functional independence, quality of life, and social participation;

2. an emphasis on a holistic, person-centered approach to care, which promotes clients' wellness and active participation in decisions about care;

3. an attempt to provide more timely, flexible, and targeted services that are capable of maximizing clients' independence. ${ }^{3}$

The UK uses the term reablement to describe short-term services with a restorative focus, developed by local authorities with responsibility for adult social care services, as part of their range of home care service provision. The development of these services was in response to broad recognition of a need for greater investment in preventive and rehabilitation services ${ }^{4,5}$ and has been actively encouraged and supported by a government initiated and funded Care Services Efficiency Delivery Program. ${ }^{6}$ The terms reablement and restorative, when applied to home care, are essentially interchangeable. In the US and New Zealand these types of services are labeled restorative home care/support services. ${ }^{7-9}$ In Australia both terms are used. ${ }^{2,10}$ Whatever the label and differences between countries in how these services have developed and are implemented by individual service providers, all have similar objectives and need to be considered when assessing the current evidence base regarding their effectiveness.

\section{Evidence for the effectiveness of reablement/restorative home care services}

Prompted by the finding that US home care frequently undermined the gains made by individuals receiving home-based rehabilitation, Tinetti et al conducted the first study on the effectiveness of restorative home care. ${ }^{711}$ They found that individuals who received restorative home care were more likely to be living at home and show greater improvement in their self-care, home management, and mobility scores at discharge than those receiving usual home care. The restorative clients also had shorter care episodes and a reduced likelihood of hospital readmission during the care episode. ${ }^{12}$ There was however no follow-up post discharge from the home care episode in this study.

At almost the same time as these restorative home care services were being developed in the US, similar services were being developed in the UK and Australia, driven by the need to curb the demand for home care, which was beginning to exceed the ability of services to meet it. ${ }^{13-15}$
The research at first took the form of service evaluations rather than research studies, and approximately two thirds of individuals who received a reablement service had no need for ongoing home care support, while many of the remaining individuals required lower levels of service after the intervention. ${ }^{16,17}$

Subsequent studies have been more rigorous, and two retrospective and one prospective UK research studies have now been completed. ${ }^{18-20}$ The first, a small retrospective study, showed a dramatic difference ( $38 \%$ compared to $95 \%$ ) in the ongoing use of home care services for reablement compared to usual home care recipients, respectively, at the 3-month review. ${ }^{18}$ The second, a larger study, investigated the longer term impact of reablement and found in three out of four services examined that at least one third of individuals who received reablement had no other home care service use, either before or up to 2 years afterward. In the fourth site, more than $80 \%$ of users had no other home care service use before or for up to 2 years afterward. ${ }^{19}$ The third and most recent UK study was designed to follow 1,000 individuals for up to 1 year after having received a reablement or a conventional home care service. ${ }^{20}$ Complete outcome and service data were collected on 382 individuals showing the reablement group to have reported greater improvements in health-related quality of life and social care outcomes and their total home care cost to be somewhat less over the year. Although the reablement group had cost more during the intervention period, they had used substantially fewer home care services post intervention.

Reablement home care services in the UK have been developed primarily to target either older people referred for social care services from the community or older persons referred when returning home after a hospital episode, less commonly both. The evidence as regards the differential effectiveness of these different service types is as yet unclear; one account suggesting that discharge services achieve better outcomes, while another reported that community-based users benefitted more than hospitalreferred users. ${ }^{6,21}$

The majority of Australian research on home care reablement has been conducted by a single home care provider. This has included an operational trial, a small nonrandomized controlled trial, and a large randomized controlled trial. ${ }^{10,14,22}$ All three studies showed that individuals who received the reablement service, the Home Independence Program (HIP), used significantly fewer home care services than individuals who received conventional home care. The smaller controlled trial found the HIP and conventional home care groups 
had similar costs over the first year of service, which was comparable to the UK findings. The randomized controlled trial however, which included home care services provided by other agencies, found that the HIP group used fewer services over 2 years and were cheaper in terms of overall home care service use both at 1 year and 2 year follow-up. ${ }^{23}$

Although not described as home care reablement, the home-based services funded through Australia's Transition Care Program, when delivered in the community, can be considered to fall into this category. The target group is older people leaving hospital, and the primary focus is to assist them to regain sufficient function to live in the community rather than be admitted to residential care. A national evaluation examined implementation of the program over a 1-year period and concluded that individuals generally experienced positive outcomes including improvements in function and a reduction in likelihood of readmission to hospital or admission to residential care when compared with patients who had not received this type of service. ${ }^{24}$ However, great variation was found between services, the cost of the service was identified as an issue, and it has subsequently been suggested that its cost effectiveness compared with other types of restorative services needs to be urgently examined. ${ }^{25}$

In New Zealand, the development of restorative home support services has been within the context of government policy support for aging-in-place initiatives, but there has been little research on the strategy's effectiveness in reducing the need for ongoing home care. A recently reported cluster randomized controlled trial did, however, find that significantly more individuals in the restorative compared to the control group had a reduced need for services postintervention. ${ }^{26}$

Summarizing the evidence to date, restorative home care/reablement has been demonstrated in the UK, US, New Zealand, and Australia to reduce the subsequent use of home care services. How long this effect lasts is currently unknown, as is whether there is any difference in effectiveness between services targeted at older people leaving hospital after an admission or older people referred for home care assistance from the community.

\section{Study objectives}

The objectives of this study were to compare retrospectively the home care use and cost over a period of nearly 5 years of older individuals who had participated in either of two reablement home care services (one targeted postdischarge and the other targeted community-based referrals) or who had received a conventional home care service.

\section{Materials and methods Research design}

A retrospective cohort study was conducted to analyze the home care service records over 57 months of older individuals who were referred to a home care provider for assistance with personal care and received either a reablement or a conventional home care service.

\section{Research setting}

Silver Chain, the home care provider in this study, delivers community-based health and home care services across the Perth metropolitan area and many of Western Australia's rural centers and surrounding areas. The conventional Home and Community Care (HACC)-funded home care services it provides are nursing, personal care, respite and domestic assistance. It is also funded, mainly in metropolitan areas, to provide home care reablement services.

\section{Reablement services}

Silver Chain provides two home care reablement services: (1) the HIP targeted at older people referred from the community (eg, general practitioner, other community care provider, self, or family) and (2) the Personal Enablement Program (PEP), which uses the HIP service model but is targeted at older people being discharged from hospital.

The HIP service model has been described in detail elsewhere. ${ }^{14}$ In summary, HIP is a short-term, individualized service designed to promote independence and minimize the need for ongoing support services. It is goal-oriented and promotes active engagement in daily living activities using task analysis and redesign, work simplification, and assistive technology. Depending on an individual's goals it may also include: strength, balance, and endurance programs for improving or maintaining function and mobility; chronic disease self-management; falls prevention strategies; medication, continence, and nutrition management; and strategies to assist the individual to reconnect socially. The HIP service usually has a 12-week time limit. PEP, like HIP, has an enablement focus, but unlike HIP, PEP can provide postacute nursing if required. $\mathrm{PEP}$ also differs from HIP by having an 8 -week time limit.

The eligibility criteria for both services include: age over 65 years, English-speaking, no known diagnosis of dementia, not receiving palliative care, and needing assistance with personal care. At the end of the reablement period, clients who need ongoing assistance with either Activities of Daily 
Living (ADLs, eg, bathing/showering) or instrumental ADLs (eg, laundry) are referred internally to receive conventional HACC home care services. Should a PEP client require ongoing nursing care, it too is provided from another service division within Silver Chain that is funded through HACC.

\section{Conventional HACC home care}

Individuals who were referred for and commenced a conventional HACC-funded personal care service during the study period were assessed by telephone to determine their eligibility, followed by a face-to-face assessment from a care coordinator who completed a care plan and scheduled the care. The most common care plan included three personal care visits a week to assist with bathing/showering, and once every 2 weeks for domestic assistance to clean and do the heavy laundry. Social support and in-home or center-based respite were also available, although used less commonly.

\section{Study cohort}

The study cohort was identified from the Silver Chain client database as having been referred to Silver Chain during the period January 1, 2004 to December 31, 2008. All members of the cohort had to meet the HIP/PEP eligibility criteria described earlier and to have received at least a "minimum dose" of intervention, which was defined as three reablement service visits or 3 hours of conventional personal care.

\section{Construction of study dataset}

Demographic and service use data from July 2004 through the end of March 2009 were drawn from Silver Chain's database. The data linkage expertise of the Western Australia (WA) Data Linkage Branch was used to source additional service assessment and service use data for the same time period relating to the WA HACC Program, Aged Care Assessment Program, and WA Mortality Register. Participants were censored if they died or were approved to enter residential aged care. However, their records were included in analyses conducted for the time periods prior to censorship.

\section{Outcome measures}

The primary outcome measure was use of home care services (yes/no) at different time points following commencement of the intervention (HIP, PEP, conventional HACC home care). The cumulative cost of home care services was examined as a secondary outcome measure. Cost data were sourced from the WA Department of Health, using 2009 unit costs as the metric.

\section{Potential confounders}

Other variables included in the analyses were: age at first visit, sex, informal carer (yes/no), living arrangement (alone/with others), previous use of HACC services (yes/no), and dependency level (low, moderate, high). Participants were defined as low dependency if they needed some help with instrumental ADLs such as using transport or meal preparation, but were independent in all ADLs such as showering, dressing, and toileting. Participants were defined as medium dependency if they needed help occasionally with any of the ADL activities. High dependency defined participants who always required help for any ADL activity.

\section{Data analysis}

Frequencies and prevalence ratios were used to describe the characteristics of the three study groups (HIP, PEP, conventional HACC) when assessed at referral (baseline). The groups were compared for the prevalence of each potential confounder using a generalized linear model.

The three groups were also compared for their use of HACC services at 3, 6, 12, 24, 36, 48, and 57 months using a generalized linear model. Two binary (yes/no) home care service measures were used: (1) any service use and (2) separately for each type of home care service use (eg, personal care, respite, domestic assistance, etc). These analyses were adjusted for all of the potentially confounding demographic variables. In all analyses, the conventional home care HACC group was used as the comparison group.

Total service costs for each group were compared at 3, 12, $24,36,48$, and 57 months. Given the nonnormal distribution of this variable and the need to adjust for potential confounders, quantile regression ${ }^{27}$ was used to compare median cost at each time point.

A 5\% level of significance was used, and all probability tests were two-tailed. Analyses and data management were performed in Stata 11 (StataCorp, College Station, TX, USA).

\section{Ethics approval}

Prior to its commencement this study received approval from the Human Research Ethics Committees of Curtin University, Silver Chain, and the West Australian Department of Health.

\section{Results Study cohort}

The cohort included a total of 10,368 individuals: 2,586 HIP, 5,450 PEP and 2,332 HACC clients. 
Participants were followed-up for a median of 2.5 years (interquartile range 1.6-3.8). Almost one third of participants ( $n=3,274,31.6 \%$ ) died during the 57-month follow-up, and 438 (4.2\%) were recommended for residential care.

There were demographic differences between the three groups (Table 1). HIP and PEP clients were less likely to have a carer, more often female and living alone, less likely to have high dependency, and less likely to have previously used home care services. They were also younger, having mean ages, respectively, of 79.33 (standard deviation [SD] 8.27) and 75.83 (SD 11.48) years, whereas the conventional HACC group had a mean age of 82.12 (SD 7.34) years, and the mean of the total sample was 78.12 (SD 10.25) years.

\section{Service use}

The HIP and PEP groups were less likely to use HACCfunded home care services of any type over the first 3 years compared with individuals who had received the conventional HACC service on referral (Figure 1). The effect in the third year remained significant only for the HIP group. The analysis of specific service types showed that the HIP and PEP groups were less likely to use personal care services, and this effect endured for the complete 57-month follow-up period (Figure 2). Again, the effect in the last year remained significant only for the HIP group.

\section{Service cost}

There was substantial cost variation within each of the three groups in the 4.5 years following the Silver Chain intervention being examined. However, a substantial difference between the groups was identified in terms of the median cumulative cost at different time points over the follow-up: both the HIP and PEP groups cost substantially less than the conventional home care HACC group (Figure 3).

As illustrated above, the median cumulative cost of all home care services in the restorative service groups was approximately half of the cost of the conventional home care HACC group at 3 months and less than one third of the cost for those followed-up for nearly 5 years. The median cumulative cost of home care in the reablement groups was $\mathrm{AU} \$ 2,364$ and $\mathrm{AU} \$ 2,563$ at 3 years and $\mathrm{AU} \$ 4,579$ and $\mathrm{AU}$ $\$ 4,793$ at 57 months for PEP and HIP, respectively, compared with AU \$11,365 and AU \$17,306 in the conventional HACC group. This translates to a median saving per person of AU $\$ 9,001$ for PEP clients and AU $\$ 8,802$ for HIP clients after 3 years and $\mathrm{AU} \$ 12,727$ and $\mathrm{AU} \$ 12,513$, respectively, after nearly 5 years.

\section{Discussion}

This study strengthens and extends the body of evidence regarding the efficacy of reablement/restorative home care services in reducing the subsequent use of home care services. It has shown that individuals who received reablement compared with a conventional home care service following referral were less likely to receive any type of home care service during the next 3 years. The magnitude of this reductive effect was greatest in relation to personal care services, both in terms of the extent of the reduction in use and the length of time that the effect lasted, in this case for nearly 5 years (57 months being the last follow-up). The size of the effect,

Table I Client demographics at referral - PEP and HIP compared with conventional HACC home care

\begin{tabular}{|c|c|c|c|c|c|c|}
\hline Variable & Level & $\begin{array}{l}\text { HACC } \\
N=2,332\end{array}$ & $\begin{array}{l}\text { PEP } \\
N=5,450\end{array}$ & $\begin{array}{l}\text { ORI }(95 \% \mathrm{Cl}) \\
P \text {-value }\end{array}$ & $\begin{array}{l}\text { HIP } \\
N=2,586\end{array}$ & $\begin{array}{l}\text { OR2 }(95 \% \mathrm{Cl}) \\
\text { P-value }\end{array}$ \\
\hline \multirow[t]{2}{*}{$\overline{\text { Age }}$} & $<78$ years & $662(28.4 \%)$ & $2,76 \mid(50.7 \%)$ & & $\mathrm{I}, 04 \mathrm{I}(40.3 \%)$ & \\
\hline & $\geq 78$ years & I,670 (7I.6\%) & $2,686(49.3 \%)$ & $0.39(0.35-0.43) 0.00$ & I,545 (59.7\%) & $0.59(0.52-0.66) 0.00$ \\
\hline \multirow[t]{2}{*}{ Sex } & Male & $853(36.6 \%)$ & $\mathrm{I}, 40 \mathrm{I}(25.7 \%)$ & & $56 \mid(21.7 \%)$ & \\
\hline & Female & $\mathrm{I}, 479$ (63.4\%) & 4,049 (74.3\%) & $1.67(1.50-1.85) 0.00$ & $2,025(78.3 \%)$ & $2.08(1.84-2.36) 0.00$ \\
\hline \multirow[t]{2}{*}{ Living arrangements } & Alone & 825 (35.4\%) & $3,09 \mid$ (57.4\%) & & $\mathrm{I}, 430(55.4 \%)$ & \\
\hline & With family & $\mathrm{I}, 504(64.6 \%)$ & $2,290(42.6 \%)$ & $0.4 \mathrm{I}(0.37-0.45) 0.00$ & I, 152 (44.6\%) & $0.44(0.39-0.50) 0.00$ \\
\hline \multirow[t]{2}{*}{ Carer availability } & No & $624(26.8 \%)$ & $3,520(65.6 \%)$ & & I,49| (57.8\%) & \\
\hline & Yes & $\mathrm{I}, 702(73.2 \%)$ & I,844 (34.4\%) & $0.19(0.17-0.21) 0.00$ & I,087 (42.2\%) & $0.27(0.24-0.30) 0.00$ \\
\hline \multirow[t]{4}{*}{ Dependency level* } & Independent & $7(0.3 \%)$ & $46(1.2 \%)$ & & $22(1.2 \%)$ & \\
\hline & Low & $594(26.5 \%)$ & $\mathrm{I}, 2 \mathrm{II}(30.3 \%)$ & $0.31(0.14-0.69) 0.00$ & $499(26.6 \%)$ & $0.27(0.1 \mathrm{I}-0.63) 0.00$ \\
\hline & Medium & $815(36.4 \%)$ & $2,405(60.2 \%)$ & $0.45(0.20-1.00) 0.05$ & I, 105 (59.0\%) & $0.43(0.18-1.01) 0.05$ \\
\hline & High & $826(36.8 \%)$ & $333(8.3 \%)$ & $0.06(0.03-0.14) 0.00$ & 247 (I3.2\%) & $0.10(0.04-0.23) 0.00$ \\
\hline \multirow[t]{2}{*}{ Previous use HACC service } & No & 976 (4I.9\%) & 3,021 (55.4\%) & & I,346 (52.0\%) & \\
\hline & Yes & $1,356(58.1 \%)$ & $2,429(44.6 \%)$ & $0.58(0.52-0.64) 0.00$ & I,240 (48.0\%) & $0.66(0.59-0.74) 0.00$ \\
\hline
\end{tabular}

Notes: *Low dependency $=$ needs assistance with one or more instrumental ADLs but no ADLs; medium = needs assistance with one or more $A D L s ;$ high $=$ totally dependent in one or more ADLs.

Abbreviations: $\mathrm{Cl}$, confidence interval; HACC, Home and Community Care; HIP, Home Independence Program; ADLs, Activities of Daily Living; OR, odds ratio; PEP, Personal Enablement Program. 


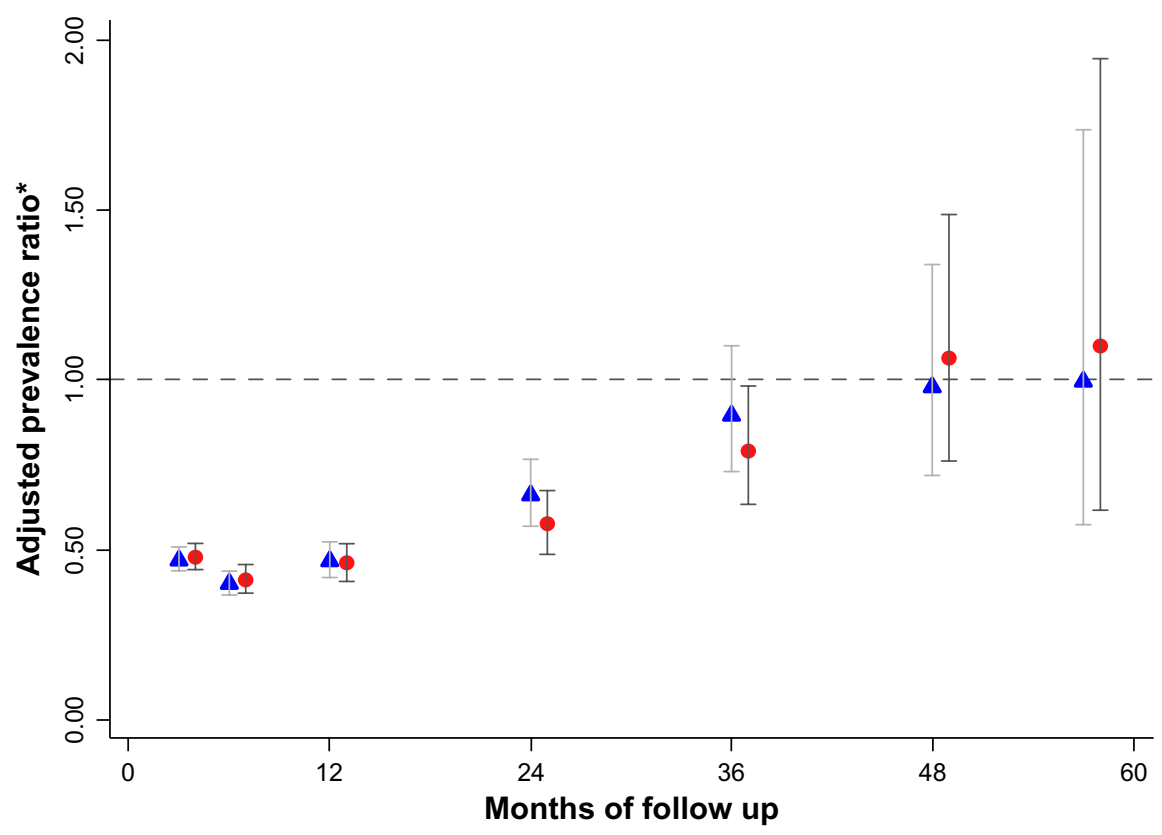

Figure I Prevalence ratio of PEP (triangles) and HIP (circles) clients in receipt of any home care service at different time points compared with conventional home care HACC group.

Note: *Adjusted for death, age, sex, living arrangement, having carer, dependency level, and receiving previous service.

Abbreviations: HACC, Home and Community Care; HIP, Home Independence Program; PEP, Personal Enablement Program.

particularly for personal care, tended to last longer for the community referred group (HIP) than for those individuals referred at discharge from hospital (PEP).

Furthermore, this study has shown that the protective effect of reablement translates directly into cost savings, noting the median cost savings for the PEP clients was slightly greater than for the HIP clients. This could be attributable to PEP having a maximum episode length of 8 weeks, whereas for HIP the maximum is 12 weeks. However, it must be noted that whereas a shorter length of stay appears on

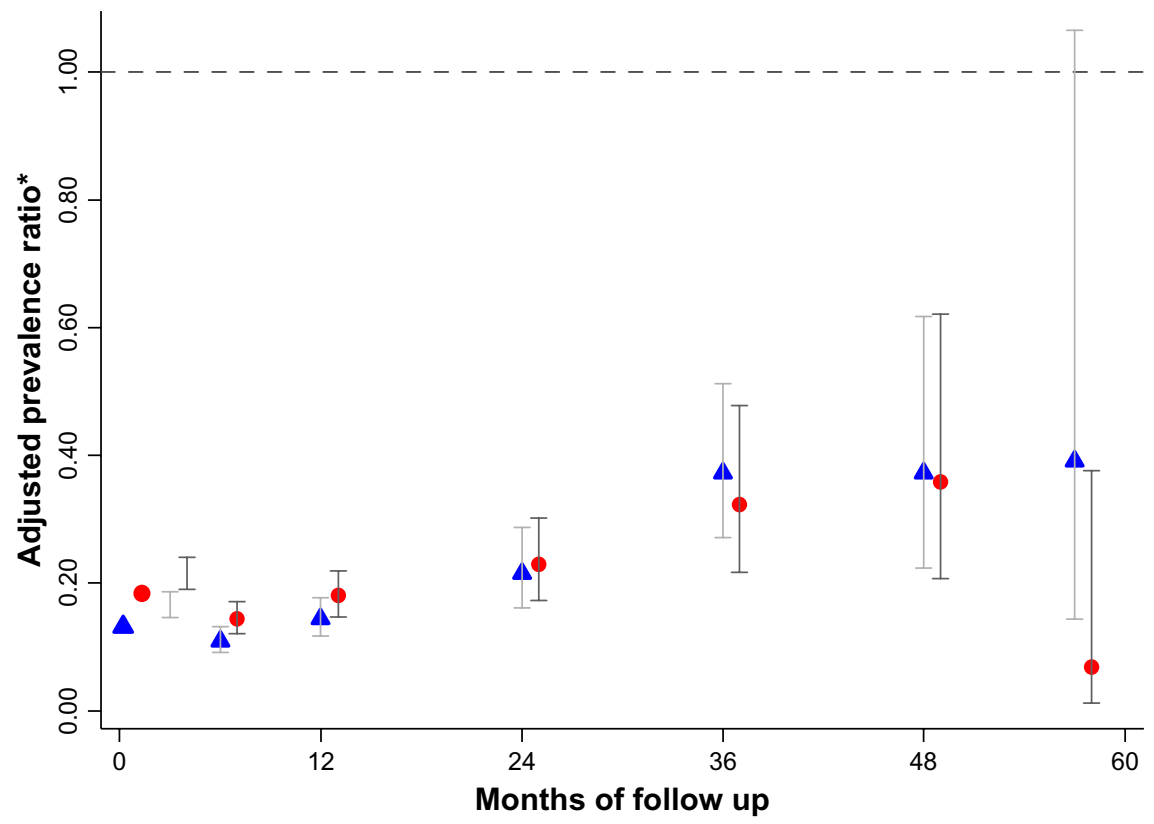

Figure 2 Prevalence ratio of PEP (triangles) and HIP (circles) clients in receipt of a personal care service at different time points, compared with conventional home care HACC group.

Note: *Adjusted for death, age, sex, living arrangement, having carer, dependency level, and requiring previous service.

Abbreviations: HACC, Home and Community Care; HIP, Home Independence Program; PEP, Personal Enablement Program. 


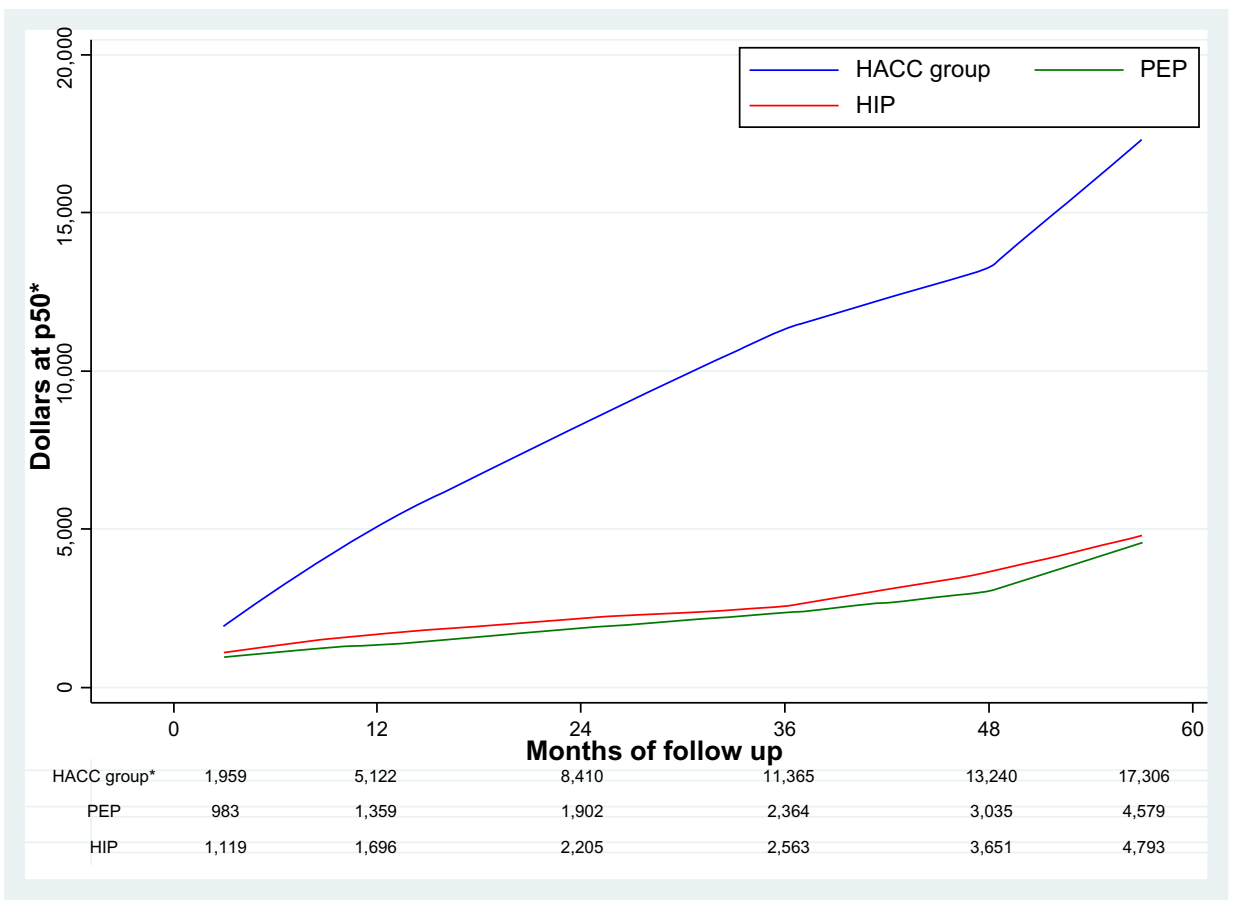

Figure 3 Median cumulative cost of all home care services received by different service recipients.

Notes: *Adjusted for death, age, sex, living arrangement, having carer, dependency level, and requiring previous service. Australian dollars as adjusted median at different time points.

Abbreviations: HACC, Home and Community Care; HIP, Home Independence Program; PEP, Personal Enablement Program.

average to have resulted in lower reablement costs, it could also be the reason for the somewhat poorer sustainability of PEP's reductive effect on service use.

This study had several advantages: sufficient sample size; a longer follow-up period than any previous study; and the ability, via data linkage, to reliably capture all available cases and, therefore, minimize potential selection bias due to loss to follow-up. However, it also had a limitation; the selective nature of the referral process produced groups that were not entirely equivalent in terms of baseline characteristics. Although we applied valid statistical techniques to adjust for these differences, residual confounding by unknown or imprecisely measured variables may have affected our results. However, it is unlikely residual confounding was large enough to account entirely for the strong associations seen in this study.

Our results are consistent with previous studies that have used comparison groups with greater baseline demographic similarity and shown the effectiveness of reablement services across diverse target groups. ${ }^{10,20}$ This suggests that it is unlikely that we have incorrectly attributed the beneficial effect to the service rather than differences between individuals. Nevertheless, further research is warranted, especially a prospective study with a follow-up of at least 5 years.

It has been suggested that the difference in service use over time between the groups could have been due to the reablement clients being at an earlier point in a trajectory of disability, and so less in need of assistance from others. This too warrants further investigation, although there is now evidence from a 10 year longitudinal study that disability in older people is episodic and reversible, rather than an inevitable ever declining trajectory as has been assumed previously. ${ }^{28}$ A prospective study that includes ongoing monitoring of disability as well as of all formal and informal assistance received is needed to improve our understanding of the relationship between service response and recovery from disability.

Our finding of a reduced subsequent need for home care for nearly 5 years is potentially generalizable to other services and situations, noting that evidence for this effect being sustained for at least 2 years already exists in different countries and service contexts. Generalizability in terms of cost savings for different services and different contexts is, however, impossible because the potential for savings is influenced heavily by the cost of the reablement service delivery model as well as the costs of the services that it is offsetting. Silver Chain's reablement model was developed within the context of HACC services, which in Australia are funded to be low level services targeted at people needing small amounts of assistance. The HIP service delivery model was therefore developed with this in mind, and it is cost effective because it uses an interdisciplinary approach 
in which, in most cases, only one health professional works with the client, and home visits are replaced by phone support as soon as feasible. UK reablement services delivered by reablement-trained nonhealth professionals have also been found cost effective..$^{20}$ In contrast, Australia's Transition Care Program, although effective in terms of assisting many people to return home rather than enter institutional care, is not cost effective because of how it is being delivered.$^{24}$ Further research is needed to identify the most cost effective service delivery model for reablement services in Australia.

\section{Conclusion}

This study has found that receiving a reablement service in comparison to a conventional home care service reduced the likelihood of using any home care service for the next 3 years and the need for a personal care service for nearly 5 years. This reduced use of home care services over time was associated with median cost savings per person of approximately AU $\$ 12,500$ over nearly 5 years when compared with individuals who had received a conventional home care service.

The routine provision of reablement rather than a conventional service when someone is referred for home care could make a significant contribution to containing the cost challenges associated with Australia's aging population. It is therefore important for all Australians that this is a key component within the design of the Living Longer Living Better aged care program.

\section{Acknowledgments}

This research was funded by the Alma Hazel Eddy Trust through Perpetual Philanthropic Services and would not have been possible without the assistance of the WA Department of Health Data Linkage Branch and the permission of the data custodians, the Aged and Continuing Care Directorate.

\section{Disclosure}

The authors report no conflicts of interest in this work.

\section{References}

1. Commonwealth of Australia. The Australian Government Response to the Productivity Commission's Caring for Older Australians Report. Canberra: Australian Government; 2012. Available from: http://www.health. gov.au/internet/main/publishing.nsf/Content/EE950B492C67A4FDCA2 579EA001699A9/\$File/D0769-Australian-Government-Response.pdf. Accessed August 28, 2013.

2. Productivity Commission. Caring for Older Australians, Report No. 53, Final Inquiry Report, Volume 1. Canberra: Australian Government; 2011. Available from: http://www.pc.gov.au/_data/assets/ pdf_file/0004/110929/aged-care-volume1.pdf. Accessed August 28, 2013.
3. Cartwright C, Cosgrave C, Gooden J, Carpenter L. Re-ablement of Older People in North Coast NSW. New South Wales: Aged Services Learning and Research Centre; 2009. Available from: http://www. google.com $\cdot a u / u r l$ ? sa $=$ t\&rct $=\mathrm{j} \& \mathrm{q}=\&$ esrc $=\mathrm{s} \&$ frm $=1 \&$ source $=$ web $\& c d=1 \&$ ved $=0$ CC4QFjAA\&url=http $\% 3 \mathrm{~A} \% 2 \mathrm{~F} \% 2 \mathrm{Fwww}$. scu.edu. au\%2Faslarc\%2Fdownload.php\%3Fdoc_id\%3D11017\%26site_ id\%3D181\%26file_ext\%3D.pdf\&ei=IlFCUv34DKm1iQft14GQBA\& usg=AFQjCNFjbvWEEAcD52Eaaf6t81CkPSrvJw\&sig2=S2cBUpJ UiVguKAxP2_cgug\&bvm=bv.53077864,d.aGc. Accessed August 28, 2013.

4. Young J, Robinson J, Dickinson E. Rehabilitation for older people. At risk in the new NHS. BMJ. 1998;316(7138): 1108-1109.

5. Nocon A, Baldwin S. Trends in Rehabilitation Policy: A Review of the Literature. London: King's Fund Publishing; 1998.

6. Care Services Efficiency Delivery Programme. Homecare Reablement Toolkit. London Department of Health; 2010. Available from: http:// interlinks.euro.centre.org/model/example/HomeCareReAblement. Accessed August 21, 2013.

7. Baker D, Gottschalk M, Eng C, Weber S, Tinetti M. The design and implementation of a restorative care model for home care. Gerontologist. 2001;41(2):257-263.

8. Lewin G. Restorative homecare services. J Curr Clinical Care. 2010;March/April:1-13.

9. Parsons M, Anderson C, Senor H, et al. ASPIRE: Assessment of Services Promoting Independence and Recovery in Elders. Auckland: The University of Auckland; 2007.

10. Lewin G, De San Miguel K, Knuiman M, et al. A randomised controlled trial of the Home Independence Program, an Australian restorative home-care programme for older adults. Health Soc Care Community. 2013;21(1):69-78.

11. Tinetti M, Baker D, Gallo WT, Nanda A, Charpentier P, O'Leary J. Evaluation of restorative care vs usual care for older adults receiving an acute episode of home care. JAMA. 2002;287(16):2098-2105.

12. Tinetti M, Charpentier P, Gottschalk M, Baker D. Effect of a Restorative Model of Posthospital Home Care on Hospital Readmissions. J Am Geriatr Soc. 2012;60(8): 1521-1526.

13. Dale P, Letchfield P. Promoting independence in Brighton and Hove. Managing Community Care. 2000;8(2):23-33.

14. Lewin G, Calver J, McCormack B, et al. The Home Independence Project. Geriaction. 2008;26(3):13-20.

15. Lewis H, Milne A. Taking Prevention Forward: A Directory of Examples. Oxford: Anchor Trust; 1999.

16. Le Mesurier N, Cumella S. Enhancing independence: the effectiveness of re-ablement provision in South Worcestershire. J Integrated Care. 1999;7(4):27-32.

17. Lewin G, Vandermeulen S, Coster C. Programs to promote independence at home: how effective are they? Generations Review. 2006;16(3/4):24-26.

18. Kent J, Payne C, Stewart M, Unell J. External Evaluation of the Home Care Reablement Pilot Project. Leicester, Centre for Group Care and Community Care Studies, De Montfort University; 2000.

19. Newbronner E, Baxter M, Chamberlain R, Maddison J, Arksey H, Glendinning C. Research into the Longer Term Effects/Impacts of Re-ablement Services. London: Department of Health Care Services Efficiency Delivery Program; 2007. Available from: http://www.york. ac.uk/inst/spru/pubs/pdf/reab.pdf. Accessed August 28, 2013.

20. Glendinning $\mathrm{C}$, Jones $\mathrm{K}$, Baxter K, et al. Home Care Re-ablement Services: Investigating the Longer-Term Impacts (Prospective Longitudinal Study). York: Social Policy Research Unit, University of York; 2010. Available from: http://www.york.ac.uk/inst/spru/research/pdf/ Reablement.pdf. Accessed August 28, 2013.

21. McLeod B, Mair M. Evaluation of City of Edinburgh Council Home Care Reablement Service [webpage on the internet]. Edinburgh: Scottish Government Social Research; 2009. Available from: http://www. scotland.gov.uk/Publications/2009/11/25100200/0. Accessed August 28, 2013. 
22. Lewin G, Vandermeulen S. A non-randomised controlled trial of the Home Independence Program (HIP): an Australian restorative programme for older home-care clients. Health Soc Care Community. 2010;18(1):91-99.

23. Lewin G. Submission to Productivity Commission Inquiry into Caring for Older Australians, submission number 114 [webpage on the Internet]. Canberra: Australian Government; 2010. Available from http://www.pc.gov.au/__data/assets/pdf_file/0011/100901/sub114.pdf. Accessed May 23, 2013.

24. Flinders Consulting. National evaluation of the transition care program: full report [webpage on the Internet], Canberra: Department of Health and Ageing; 2008. Available from: http://www.health.gov.au/ internet/publications/publishing.nsf/Content/ageing-transition-nationalevaluation-report.htm. Accessed August 28, 2013.
25. Cameron ID, Crotty M, Gray L. Whither transition care. Australas J Ageing. 2010;29(4):147-149.

26. King Al, Parsons M, Robinson E, Jörgensen D. Assessing the impact of a restorative home care service in New Zealand: a cluster randomised controlled trial. Health Soc Care Community. 2012;20(4):365-374.

27. Stoltzfus J, Nishijima D, Melnikow J. Why quantile regression makes good sense for analyzing economic outcomes in medical research. Acad Emerg Med. 2012;19(7):850-851.

28. Hardy SE, Gill TM. Recovery from disability among communitydwelling older persons. JAMA. 2004;291(13):1596-1602.
Clinical Interventions in Aging

\section{Publish your work in this journal}

Clinical Interventions in Aging is an international, peer-reviewed journal focusing on evidence-based reports on the value or lack thereof of treatments intended to prevent or delay the onset of maladaptive correlates of aging in human beings. This journal is indexed on PubMed Central, MedLine, the American Chemical Society's 'Chemical Abstracts

\section{Dovepress}

Service' (CAS), Scopus and the Elsevier Bibliographic databases. The manuscript management system is completely online and includes a very quick and fair peer-review system, which is all easy to use. Visit http://www.dovepress.com/testimonials.php to read real quotes from published authors.

Submit your manuscript here: http://www.dovepress.com/clinical-interventions-in-aging-journal 